\title{
Aggression and Perception of Pain among Young Candidates to Professional Soccer Players
}

\author{
Katia Rubio', Ivan Rabelo1,2, Gabriela Gonçalves ${ }^{3}$ \\ ${ }^{1}$ School of Physical Education and Sport, University of São Paulo (EEFE/USP), São Paulo, Brazil \\ ${ }^{2}$ Ayrton Senna Institute (IAS), São Paulo, Brazil \\ ${ }^{3}$ Heart Institute of São Paulo (Incor-HCFMUSP), São Paulo, Brazil \\ Email: katrubio@usp.br
}

Received 8 November 2014; revised 19 December 2014; accepted 3 January 2015

Copyright (C) 2015 by authors and OALib.

This work is licensed under the Creative Commons Attribution International License (CC BY). http://creativecommons.org/licenses/by/4.0/

(c) (i) Open Access

\begin{abstract}
Aggression is a constant feature in an athlete's life. This is because training and too many competitions require a proactive attitude to these demands, hence the importance to distinguish aggression and violence. The same demands that generate aggressiveness also cause pain and injury due to excessive training and competitions. The influences and guidance experienced in the early formation of an athlete's career are related to other aspects of personality like aggression, perception of pain and effort developed during an athlete's history and his interaction with the environment. This study evaluated 87 adolescent athletes from the base team of a large professional soccer club in the city of São Paulo through the application of psychological assessment tests. The results showed differences among different subgroups of adolescent athletes, as well as differences between these results and normative data described in the manuals of instruments used. When comparing the results from groups of the Brazilian sample of this research with the results of subjects included in the original German manual, the results show much higher average scores in the sporting context.
\end{abstract}

\section{Keywords}

Sports Psychology, Psychological Assessment, Pain, Aggression, Physical Education

Subject Areas: Psychology, Sports Science

\section{Introduction}

One of the aspects that interact with athletes and sportsmen in their daily activity is the challenge to overcome, 
the search for the best results, the achievement of goals, etc. The achievement, which is one of human pretensions, becomes even more important in seeking to overcome limits in sports. This search for limits is related not only to the duration of events, but also to how much an individual is submitted to intense physical and mental effort.

However, in adolescent development, physical activity can help reduce the risk of future diseases and has significant psychosocial effects. There are many myths about physical exercise in adolescence and many doubts about the exact influence of sport in phenomena such as skeletal growth and sexual maturation. Moreover, unlike expected, physical activity in this age group is not exempt of risks, and these risks include body injuries and nutritional deficiencies [1].

According to Barbosa [2], competition-level sport with dedication to training and increasing workload could contribute for adolescents to approach sport definitely, to frequent practice, with positive effects on their life. On the other hand, it can cause discouragement if they do not achieve the results desired by them or by their family. This search for results can also lead to increased risks involved in training. According to the author, the practice of sports should not prevent the development of other capabilities in the field of culture, music, arts and media. Sport seen as only or main activity of adolescents can be harmful due to the enormous pressure to excessive physical exertion, causing anxiety resulting from competitions and training, which can lead them to imbalances with respect to their physical and emotional satisfactions.

Athletes constantly deal with lesions either of higher or lower intensity. According to Engstrom, Johansson, Tornkvist and Forssblad [3], about 5\% - 15\% of elite athletes are out of training for at least one month in each season due to injuries. Such lesions have negative implications on the athlete's health and could adversely affect his training and performance [4]. Living with small or large lesions, training or playing with pain seems to be almost certain and acceptable experiences in the life of a sportsman [5]. Athletes seem to have similar pain thresholds of non-athletes, and although they are more tolerant to pain, the exact cause of this increased tolerance remains unknown [6].

In recent studies, [7] [8] report that the athlete is able to recognize different forms of pain, referred to as training pain and lesion pain, although the thresholds involved in the training pain that contribute to the appearance of lesions are still unknown.

Knowledge of these thresholds is possible when recognized individual characteristics are directly related to contextual aspects and socio-emotional, such as age, sex, social class, temperament, personality, anxiety, stress, previous experience, resilience, etc. Knowledge of these features can assist in various situations such as 1) individualizing mode of information delivery in the performance and learning of tasks, 2) adequately organizing the environment where tasks will be performed, and 3) selecting people with better profile to perform certain functions or tasks [9].

Given that aggression is an aspect to be investigated regarding someone's personality in sport, particularly in soccer, studies have linked aggression to different factors such as the situation of visited or visitor, the degree of importance of the game itself, the performance level of players, the player's position and tactical task, the behavior of coaches and officials and the sport rules. Dogan [10] showed that the athletic participation of soccer players and non-athletes and the anxiety trait play a significant role on their aggression out of sport.

Aggression in sport becomes a social issue and may reflect broader social tensions and aggressiveness in the society itself. Aggressiveness in sport practice reflects sociological, personality and athlete training factors, factors associated with training and competition (coach, fans, and sports context), and broader social factors, for example, how the theme appears in the media [11].

Among the factors that characterize the differences among people, personality and emotional characteristics are highlighted, although a fully defined concept of the term personality does not exist in the scientific community. Rather, there are a large number of theorists who, based on different assumptions and different types of measures, seek a unifying principle that explains the consistency of behaviors observed among people.

Among the different types of instruments used to assess personality, inventories and scales stand out. International research has shown that these tools are among the most used for personality assessment in collective applications as they provide valuable data to clinical practice [12]. In addition, assessing personality through questionnaires often provides benefits over unstructured tools, since their items are empirically selected [13].

However, there are no personality instruments adapted to the Brazilian reality in the sporting context. According to Rubio [14], the incorporation of psychological assessment in the process of physical training and issues related to population health, among others, enhances the knowledge about the capabilities and limitations of 
each individual, thus contributing to clarifying the effects of sport and exercise on the lives of sportsmen. All psychological tests can be used in sports psychology under the following conditions: they must be properly validated and standardized for the Brazilian reality, adapted to the sports field, and applied and evaluated by trained psychologists, since misinterpretation can cause serious damage to mental health of athletes [15].

In general, and for the majority, instruments for psychological assessment validated and standardized for Brazil have no research to populations in sporting context. Thus, such instruments do not meet the specific needs of sports psychology and therefore further studies should be conducted to validate the interpretation of tests for the sporting context.

Faleiros and Sousa [16] point to the theoretical, methodological and clinical importance of measuring the psychometric properties of rating scales. It was observed that although conceptual and psychometric difficulties still remain in studies carried out with scales, it is possible to observe progresses both in construction and in the application of these scales that reach several criteria considered ideal in a process of pain measurement and assessment.

Information obtained through psychological testing, especially personality tests, may be useful in the work of the psychologist with the athlete, as they provide better understanding of the psychic condition of this athlete in the evaluation period. It enhances the psychologist's action, making it potentially more effective and useful for the coach's work (when guiding over the entire evaluation process) and also a support for the athlete. Tests are very useful for athletes when they are able to perceive and rethink about their behaviors and attitudes based on the results obtained by assessment tools, contributing to achieving their goals.

The objective of this research was to evaluate the integration of factors related to aspects of personality, aggressiveness and perception of pain and effort in 87 adolescent athletes of the base team of a professional football club in the city of São Paulo.

\section{Method}

Based on introductory information presented, the aim of this study was to assess dimensions of aggression and perception of pain by adolescent athletes from the base team of a large professional soccer club in the city of São Paulo through the application of psychological evaluation tests. Thus, 87 male high-school students contributed to the development of this study. The age of participants ranged from 14 to 15 years $(\mathrm{M}=14.47, \mathrm{SD}=$ 0.50 ). Of these, $32.2 \%$ are from other states and are housed at the club, and the rest are residents of the city of São Paulo and surroundings.

Regarding the instruments used in the research, the first one refers to the Brief Questionnaire for Identifying Factors of Aggression (FAF-K). The first edition of the instrument was published by Hampel and Selig in 1975, which is the result of works at the University of Freiburg. For over 30 years, the Questionnaire for Identifying Factors of Aggression (FAF; Hampel and Selig, 1975) is internationally used in germanophonic regions, which underwent revisions relating to the questionnaire items, giving rise to the Brief Questionnaire for Identifying Factors of Aggression (FAF-K). The reduced version presented here has been largely improved by Heubrock and Petermann at the University of Bremen.

Conceptually, FAF-K is guided by models of the learning psychology of aggressive behavior (social-cognitive learning theory according to Bandura). Individual differences in aggressive behavior (e.g. opinions on violence and violence-related standards) and situational characteristics (cognitive stimuli, frustration, assault, drugs and body fatigue) are considered. The mutual relationship between dispositional factors and individual learning experiences results in a relatively stable tendency (in the sense of a propensity) of behaving aggressively (Aggressiveness).

Factor 1, called Spontaneous Aggressiveness, refers to the imaginary, verbal or physical aggression towards people and animals even for the most sadistic tendencies. People with high scores are described as relatively uncontrolled and people with low scores are considered controlled, calm and passive. The instrument standardization research showed that as age advances, there is a drop in scores. Men achieve mean higher scores than women. Students have relatively low scores, while criminals have relatively high scores.

Factor 2, Reactive Aggression, is related to aggression socially sanctioned at a large extent. High scores on this factor mean a desire of imposing through conformist attitudes, while low scores indicate a tendency to refuse the aggressive behavior style.

In Factor 3, Irritability, susceptibility is approached. High scores indicate multiple experiences of boredom, 
hatred and rage, as well as lack of control of emotions and low tolerance to frustration. Sequentially, Factor 4, Self-Aggression, includes self-accusations, depressive mood, resentment and mistrust. High scores indicate depressive tendencies, dissatisfaction and negative view of life. Low scores mean a balanced state of mind.

Finally, Factor 5, Aggression Blocking, describes aggression blocking or blocking in general. However, high scores manifest under certain conditions only knowledge about the rules of the game. FAF research revealed higher scores with increasing age in females and in clinical groups.

This scale also includes an index of Sum of Total Aggression, referring to the field of global affirmation that incorporates the propensity for externalizing aggression, and scores tend to decrease with increasing age. Males achieve higher scores than females, according to the authors of the instrument.

The other instrument used was the Sport Inventory of Pain - SIP [17], which is an instrument specific for sport that measures five subscales relevant to competition: direct coping (COP) cognitive (COG), catastrophizing (CAT), avoiding (AVD) and body awareness (BOD). The inventory also contains a score equivalent to the Total Coping Response Score-TCR $=\mathrm{COP}+\mathrm{COG}-\mathrm{CAT}$, which is a general indicator of the athlete's ability to play his role when experiencing physical injury or painful situations.

The first four subscales (COP, COG, CAT and AVD) represent different ways of coping with pain. The direct coping - COP scale seems to measure the amount of immediate attention the athlete pays to pain, discomfort and injury during competition. Athletes who have high scores in this regard tend to ignore pain, understanding pain as part of the competition and usually have an attitude of "go over" pain. One of the questions related to this item in the inventory is as follows: "when I'm hurt, I tell myself I cannot let pain get in the way of what I want to do".

The cognitive-COG scale measures the use or nonuse of mental strategies such as imagery in situations where it is necessary to deal with pain. Individuals with high scores on the direct coping scale tend to score high on the cognitive scale, thus demonstrating ability to incorporate and use large amount of mental techniques to keep the focus on the task. An example that fits that category is "when I feel pain, I mentally recall great performances of the past".

Catastrophizing - CAT subscale detects individuals who tend to despair with the presence of injury, those who become pessimists, who think in pain all the time, feel that it is impossible to tolerate and essentially give up their condition. Avoiding - AVD scale was in turn designed to measure how many avoiding strategies a person uses to deal with pain. Individuals with high scores on this subscale appear to be less competitive when injured. One item related to avoiding would be "When I'm hurt, I worry all the time if pain will end or not". New data obtained with this inventory have shown that avoiding is not always negative: elite athletes often have high scores on this scale because when injured, they tend to direct efforts and activities for the competition itself, when it really matters.

Body Awareness - BOD subscale measures whether the individual is hypersensitive or hyposensitive to painful stimulus. Thus, it was meant to serve as a possible covariate in studies of pain with athletes emerging as a strong predictor of response to pain and sports performance in some populations of athletes.

Inventory items were designed according to predefined techniques of scale construction [18] and are scored by a 5-point Likertscale. SIP has proven to be a reliable predictor of psychological stress and consequent physiological response induced by pain situations. Adequate internal consistency (Cronbach alpha $=0.61-0.88$ ), testretest reliability ( $r=0.69$ to 0.86 ) and low social desirability (Marlowe-Crowe $r=-0.28$ to -0.13 ) were established in some studies involving populations of adolescent athletes in non-contact sports [19].

Data collection lasted four weeks, held during the month of November 2012. After contacting the institution (professional soccer base club) and obtaining authorization from parents or guardians through signing the Informed Consent Form (ICF), an initial contact with adolescents was made, which was intended to inform about the research objectives. Subsequently, the instrument was collectively applied in day and time previously established. For data analysis, SPSS version 17.0 was used.

\section{Results and Discussion}

Considering the objectives of the present study, the following information refers to the results obtained from data collection using the instruments in all subjects included in the sample. Figure 1 shows the results of scores in the instruments investigated.

From an initial visual inspection, Figure 1 shows that in variable TCR corresponding to the total related to 

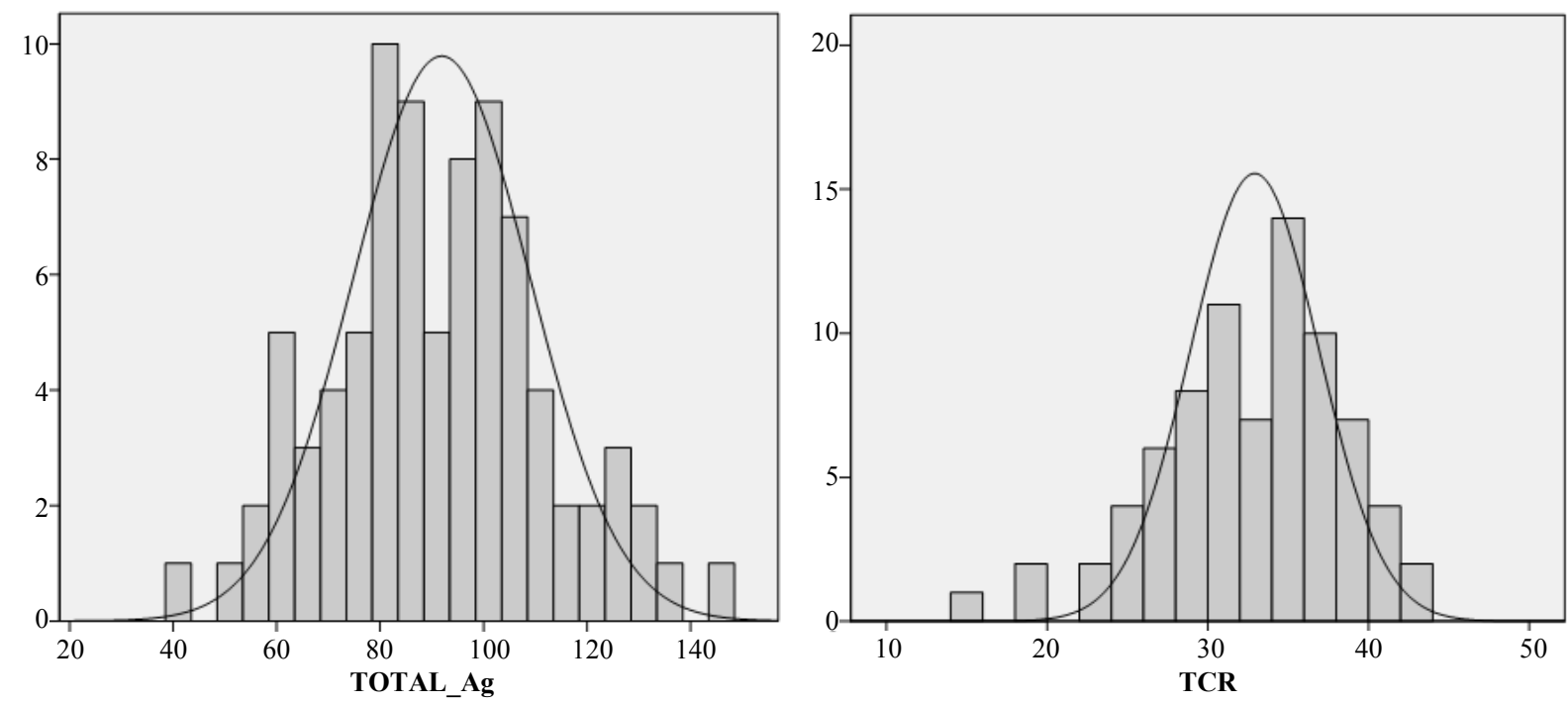

Figure 1. Graphs of total scores.

SIP test, participants obtained scores somewhat higher, although this visual difference seems to be little significant. In turn, participants showed a more concentrated distribution in relation to the average in variable total score in the FAF-K test.

In relation to reliability studies, such accuracy rates were estimated by means of the Cronbach's alpha coefficient for the total sample as well as separately by factors for each instrument. The accuracy of the FAF-K instrument was verified, whose Cronbach alpha coefficient was 0.89 for the total items, which is considered very good for this type of scale.

Regarding the SIP test, which showed Cronbach's alpha coefficient of 0.50 , it was found that this measure showed a reasonable level of accuracy; however, below the minimum desirable, as proposed by Pasquali [20], is 0.70. In this type of task using scales, coefficients indicate average reliability.

As indexes are shown near satisfactory levels, i.e. greater than 0.70 in most factors and the full FAF-K scale, it could be inferred that this test showed a good level of accuracy, being considered a reliable instrument for measuring the respective constructs in this group. However, lower indexes in relation to Self-Aggression and Aggression Blocking factors were observed, which showed Cronbach's alpha of 0.54, suggesting that the results of this factor should be interpreted with caution.

In relation to the accuracy results provided by the SIP instrument, Cronbach's alpha indexes below the minimum desirable are observed. These results suggest caution in the interpretation of results derived from this instrument in the investigated sample, while they suggest the need for more studies on the SIP instrument and its respective latent construct in the sporting context.

Comparisons of results observed between the international instrument and the Brazilian sample in the sporting context will be held. Information on means and standard deviations of factors and total FAF-K test can be seen in Table 1.

When comparing the results of the mean scores among subjects from Under 14 with Under 15 groups, it was observed that the first group had higher averages in relation to the latter, in particular regarding the sum of aggression, demonstrating that such individuals were more prone to aggressive behavior. Although dealing with different groups and modalities, Ryan, Williams and Wimer [21] concluded that giving legitimacy to aggressive acts was more common among basketball players in the first year than among experienced players, but their results showed lower levels of aggression among beginners than among more experienced athletes.

To obtain values for comparison with the original FAF-K manual sample, this was composed of healthy nondelinquent subjects $(\mathrm{N}=937)$. Of subjects from the reference sample aged between 18 and 75 years $(M=33.01$, $\mathrm{SD}=12.52), 218$ were male $(55 \%)$ and 179 were female $(45 \%)$. In the elaboration of the reference sample, two aspects were favored: an age division corresponding to domains of FAF application and the exclusion of people already fined for criminal reasons or disturbance to public order. Since the amount of adolescents contemplated by judicial pension and persons in the young-adult age range is considerably larger, the reference sample is 
Table 1. Descriptive statistics of FAF-K scores.

\begin{tabular}{cccccccccc}
\hline & \multicolumn{2}{c}{ BR sub 14 sample } & \multicolumn{2}{c}{ BR sub 15 sample } & \multicolumn{2}{c}{$\begin{array}{c}\text { Orinal manual sample } \\
\text { (German) }\end{array}$} & \multicolumn{2}{c}{$\begin{array}{c}\text { Delinquents sample } \\
\text { (German study) }\end{array}$} \\
\cline { 2 - 10 } FAF-K factors & $\mathbf{M}$ & SD & M & SD & M & SD & M & SD \\
\hline Irritability (excitability) & $\mathbf{1 8 . 9 1}$ & 7.273 & $\mathbf{1 6 . 6 8}$ & 7.431 & $\mathbf{1 0 . 2 5}$ & 6.31 & $\mathbf{2 2 . 6 0}$ & 11.49 \\
Self-aggression & $\mathbf{1 3 . 9 1}$ & 4.623 & $\mathbf{1 2 . 9 3}$ & 4.59 & $\mathbf{1 8 . 3 7}$ & 7.27 & $\mathbf{2 9 . 5 2}$ & 12.49 \\
Reactive aggression & $\mathbf{2 3 . 2 1}$ & 7.186 & $\mathbf{2 2 . 7 3}$ & 6.5 & $\mathbf{1 4 . 8 0}$ & 7.39 & $\mathbf{2 9 . 8 7}$ & 10.12 \\
Spontaneous aggression & $\mathbf{1 3 . 1 4}$ & 7.143 & $\mathbf{1 1 . 6 8}$ & 6.854 & $\mathbf{1 2 . 5 0}$ & 6.71 & $\mathbf{2 2 . 3 2}$ & 6.25 \\
Aggression blocking & $\mathbf{2 5 . 0 2}$ & 4.056 & $\mathbf{2 4 . 9 0}$ & 4.898 & $\mathbf{1 9 . 8 1}$ & 5.03 & $\mathbf{1 7 . 1 7}$ & 6.10 \\
Sum of aggression & $\mathbf{9 4 . 1 9}$ & 21.413 & $\mathbf{8 8 . 9 3}$ & 19.842 & $\mathbf{4 3 . 4 2}$ & 17.30 & $\mathbf{8 1 . 9 8}$ & 31.84 \\
\hline
\end{tabular}

largely composed of adolescents and young adults.

When comparing the results from groups of the Brazilian sample of this research with the results of subjects included in the original German manual, the results show much higher average scores in the sporting context. These results corroborate the research [11] which assessed the aggressive behavior of 125 Portuguese senior soccer players who belonged to the First League of the Portuguese Championship from 2000 to 2001 and 88 players from the junior level subdivisions aged 17 - 18 years. Senior players aged from 20 to 35 years, while juniors aged from 17 to 19 years. The study involved the application of the Bredemeier Athletic Aggression Inventory (BAAGI), and the results suggested that senior players had higher rates of reactive or hostile aggression, with a statistically representative assessment of the number and type of cards (yellow and red) received by the athletes and their self-assessments in terms of aggression, confirming the hypothesis of the need for a somewhat higher measurement of aggressiveness in athletes.

However, it should be observed from data of this study that in relation to Self-Aggression factor, which refers to "self-accusations, depressive mood, resentment and mistrust, in which higher scores indicate depressive tendencies, dissatisfaction and a negative view of life, while low scores manifest a balanced state of mind", the averages of groups in the sporting context are more lowered when compared to the reference group of the German manual, demonstrating higher state of mind and energy for the action, necessary for competition and also opposite to depressive tendencies.

Regarding the subjects from the FAF-K manual sample consisting of delinquent subjects aged $16-63$ years $(\mathrm{M}=28.93, \mathrm{SD}=12.07), 54$ males and 6 females, the group of delinquents was selected among persons under condemnation or legal determination, for example, under a conditional suspension of sentence under therapeutic guidance due to at least one violent crime in institutions either as adolescents complying socio-educational sentence, or as adults complying sentence or detention order. A smaller proportion of women in the sample of offenders reflected their overall participation in violent crimes. In contrast, the division by gender in the reference sample was balanced.

Thus, when data from the group in the sporting context were compared with the sample of offenders from the original German manual, much higher levels of aggression were observed in the second group, which also allowed us inferring that despite the need for aggression in the sporting context, this did not compare to the level of aggression contained in samples with more aggressive propensity, related to subjects who committed crimes or made some kind of law violation. Two factors in particular may be important in the differentiation of high aggression contained in athletes compared to sample composed of offenders. As can be seen from Table 1, it appears that the reactive aggression in the sample of athletes is high in relation to the normalization sample of the German manual composed of subjects without history of aggressiveness, tending towards an approximation of the sample of offenders, although the indexes showed by offenders are still higher than those of athletes.

Considering the representation of reactive aggression factor that states "high scores on this factor mean a desire of imposing through conformist attitudes, while low scores indicate a tendency to refuse the aggressive behavior style", it could be inferred that in the sporting context, the "use" of aggression is allowed as a boost for competition, but not at levels as high as offenders as to actually oppose the enforcement of rules and laws.

This becomes even more evident when comparing a second factor called Aggression Blocking, in which the samples in the sporting context show results much higher than the samples of offenders who have very low Aggression Blocking indexes, even regarding the standardization group of the German manual; the sports team still 
has much higher Aggression Blocking indexes. So, knowing that the factor describes Aggression Blocking or blocking in general, in which high scores manifest under certain conditions, only knowledge about social rules, without necessarily following them; these results allow us concluding that despite the need for athlete to make use of aggression as vital energy for action, sports practice and above all aimed at competition, a high propensity for Aggression Blocking at different times is also necessary.

Another study proposed by this research aims to investigate how adolescent athletes candidates to professional soccer players behave in relation to the perception of pain. Comparisons of results observed between the international instrument and the Brazilian sample in the sporting context were performed, also compared to another survey with Brazilian athletes using the same instrument. Information on means and standard deviations of factors and total (TCR) of the SIP test can be seen in Table 2.

When the results of the mean scores between groups aged 14 and 15 years were compared, it was observed that most factors showed no difference between groups. However, the Under 14 group showed a little lower averages than Under 15 group factor cognitive scale (COG) and also in relation to total pain coping (TCR), which might be an indication that the latter group, for being longer at the club and participating in competitions, had cognitive and pain coping strategies better adapted to the reality of the sport professional.

Considering the significance of COG factor that "measures the use or nonuse of mental strategies such as imagery in situations where it is necessary to deal with pain, thus demonstrating the ability to incorporate and use of a large amount of mental techniques to maintain focus on the task, tending to distract from pain", it could be inferred that the second group, being more trained, has also more strategies to deal with pain.

This is corroborated by the results found between groups, which in the scale of total pain coping (TCR), the indexes of the group aged 15 years is also higher than the group aged 14, indicating that adolescents from the older group possibly show better ability to play their role when experiencing physical injury or painful situations than the younger group.

Reflecting on mental strategies used by athletes in the experience of pain episodes is an important factor for obtaining high performance. Pain is a constant presence in the lives of high-performance athletes, hence its association with the agonistic represented in seeking and overcoming limits, as well as perseverance observed in the construction and pursuit of better athletic shape [7] [8] [22]. The personal and social costs for athletes who live in this production system result in problems such as coping with constant injury and the shortening of their careers. Thus, pain arises as a constant companion in the athlete's life, which varies in form and intensity.

When comparing the results of adolescent athletes with a study [22] in a sample of Brazilian elite athletes, it was observed that the group of professionals showed a little lower average for the catastrophizing factor. Catastrophizing subscale refers to individuals who tend to despair with the presence of injury; those who become pessimists, who think in pain all the time, feel that it is impossible to tolerate and essentially give up their condition, thus, it could be inferred that these professional athletes have already learned through practice and experience in competitions to have greater control over this overvaluation of pain.

Such discussions about the threshold between bearing pain or perceiving it in time for an injury to occur are something much discussed in the sporting context. Pain has different ontologies, acquiring own meanings and depending on each context. When speaking of pain in sport, we are dealing with a completely different phenomenon of pain represented in everyday life. Social and cultural contexts play an important role in determining the meaning of pain, so this sensation can be taken by the individual as a positive sign or rejected as a negative sign that should be corrected or avoided [23].

\section{Table 2. Descriptive statistics of the SIP scores.}

\begin{tabular}{ccccccc}
\hline \multirow{2}{*}{ SIP factors } & \multicolumn{2}{c}{ BR Under 14 sample } & \multicolumn{2}{c}{ BR Under 15 sample } & \multicolumn{2}{c}{ High-performance athlete sample BR ${ }^{* *}$} \\
\cline { 2 - 7 } & $\mathrm{M}$ & $\mathrm{SD}$ & $\mathrm{M}$ & $\mathrm{SD}$ & $\mathrm{M}$ & SD \\
\hline Direct coping (COP) & 28.16 & 3.404 & 28.66 & 3.497 & 28.31 & 4.71 \\
Cognitive scale (COG) & 15.27 & 2.423 & 17.49 & 2.899 & 16.66 & 2.90 \\
Catastrophizing (CAT) & 12.65 & 1.903 & 12.85 & 2.140 & 10.44 & 1.97 \\
Avoiding (AVD) & 13.86 & 2.275 & 13.68 & 2.196 & 13.88 & 2.55 \\
Body awareness (BOD) & 11.35 & 2.150 & 11.85 & 2.286 & 11.56 & 1.98 \\
Total coping (TCR) & 30.78 & 5.884 & 33.29 & 5.100 & 34.53 & 6.20 \\
\hline
\end{tabular}

${ }^{* *}$ Silva, Rabelo and Rubio, 2010. 
Assessing whether possible variations between results of adolescents who made up Under 14 and Under 15 groups were statistically significant, a student's t-test of scores on these instruments was performed. Regarding the difference between groups with respect to the FAF-K instrument, although averages presented some differences, as described in previous paragraphs, these findings were statistically not significant. Regarding the SIP test, differences between groups in variable COG and also in relation to total coping (TCR) were significant, supporting the hypothesis that the difference between subgroups is not random in these factors, allowing inferring that previous hypotheses, in which Under 15 group presented a more appropriate and suitable strategy for coping with pain compared to those from the Under 14 group, demonstrating the importance of participation in this type of program for professional development of the athlete, and preparing them for future practice.

To evaluate the influence of variable age on the studied data, the Pearson correlation test with significance level of 0.05 was performed to analyze differences in the factors of instruments. To interpret the observed correlations, the categorization of the interpretation of correlation coefficients according to Duffy, Mclean and Monshipouri [24] was used, in which a coefficient value from 0.00 to 0.19 was interpreted as "not related or neglected relationship", from 0.20 to 0.29 as "weak relationship", from 0.30 to 0.39 as "moderate relationship", from 0.40 to 0.69 as "strong relationship" and from 0.70 to 1.00 as "very strong relationship". However, specifically in this study, the results suggested no significant correlations in relation to variable age and the scores achieved by participants in the FAF-K test.

Regarding the SIP test, significant positive correlations of one of factors and total pain coping in relation to variable age, moderate $(r=0.38 ; \mathrm{p}<0.001)$ with variable $\mathrm{COG}$ and weak $(\mathrm{r}=0.23 ; \mathrm{p}<0.05)$ with variable TCR were observed. These results corroborate studies comparing the two groups, Under 14 and Under 15, previously described.

Studies have been performed with the aim of analyzing the behavior of variables investigated in relation to both instruments, with the possibility of verifying relations between aggression and pain perception. Unlike previous studies, the sample of adolescent athletes will be grouped, i.e. the results correspond to the entire sample investigated (Under $14+$ Under 15).

To investigate the relationship between characteristics of the FAF-K scale and the results presented by the SIP test, the Pearson correlation test with significance level of 0.05 was also used. The results of these analyses showed amplitudes of significant correlations. These data can be seen in Table 3 .

With regard to the correlation between instruments, although no significant correlation was observed between total aggression (FAF-K) and total coping (SIP), a statistically significant negative and weak $(\mathrm{r}=-0.23 ; \mathrm{p}<$ 0.05 ) correlation was verified between total pain coping (TCR) and reactive aggression factor of the FAF-K test, allowing inferring that there was an inverse relationship between variables, i.e. subjects with higher reactive aggression index tended to have lower ability to play their role when experiencing physical injury or painful conditions.

A statistically significant weak positive correlation was also observed $(r=0.23 ; p<0.05)$ between aggression blocking and the cognitive scale (COG) of the SIP test, which suggested that subjects who had high score in aggression blocking tended to have higher indexes of use of mental strategies such as imagery in situations where it was necessary to deal with pain. Finally, weak and moderate correlations, respectively, are found between catastrophizing factor of the SIP test and spontaneous aggression $(\mathrm{r}=0.28 ; \mathrm{p}<0.05)$, and reactive aggression factors $(r=0.30 ; p<0.001)$, both significant and positive.

Table 3. Correlation between characteristics and the total factor of K-FAF and SIP tests $(N=75)$.

\begin{tabular}{|c|c|c|c|c|c|c|c|}
\hline & & $\begin{array}{c}\text { Spontaneous } \\
\text { aggress. }\end{array}$ & $\begin{array}{l}\text { Reactive } \\
\text { aggress. }\end{array}$ & $\begin{array}{c}\text { Irritability } \\
\text { (excitability) }\end{array}$ & Self-aggression & $\begin{array}{l}\text { Aggression } \\
\text { blocking }\end{array}$ & $\begin{array}{c}\text { Sum of } \\
\text { aggression }\end{array}$ \\
\hline Direct coping (COP) & $r$ & -0.11 & -0.08 & -0.07 & -0.07 & 0.06 & -0.09 \\
\hline Cognitive scale (COG) & $r$ & -0.12 & -0.14 & -0.10 & -0.10 & $0.23^{*}$ & -0.09 \\
\hline Catastrophizing (CAT) & $r$ & $0.28^{*}$ & $0.30^{* *}$ & 0.12 & 0.21 & 0.11 & $0.31^{* *}$ \\
\hline Avoiding (AVD) & $r$ & 0.12 & 0.03 & 0.02 & -0.04 & 0.04 & 0.06 \\
\hline Body awareness (BOD) & $r$ & -0.04 & 0.01 & -0.11 & -0.05 & 0.10 & -0.04 \\
\hline Total coping (TCR) & $r$ & -0.23 & $-0.23^{*}$ & -0.14 & -0.17 & 0.17 & -0.22 \\
\hline
\end{tabular}

Note: ${ }^{* *} \mathrm{p}<0.001 ;{ }^{*} \mathrm{p}<0.05$. 
These coefficients allow us to infer that subjects with higher tendency to aggression tend to despair over the presence of injury, to have pessimistic thoughts, and to think more intensely about pain. Still regarding the relationship between aggressiveness coefficients and the catastrophizing factor, such relationship is also evident when verifying a positive and statistically significant moderate correlation between catastrophizing and total aggression captured by FAF-K in the study group.

Finally, to investigate the relationship between the features of the FAF-K scale and the interrelationship between factor and total aggression, the Pearson correlation test with significance level of 0.05 was used. Therefore, very strong correlations were observed among the four factors and the total aggression and among factors, except for blocking factor, which is little associated with the other factors, always showing negative correlations, allowing inferring that the control (blocking) is opposed to other factors that make up aggressiveness according to the instrument. It is noteworthy that most of the correlations with the other factors despite negative, were not statistically significant except for the correlation between blocking of aggression and self-aggression, which showed low and negative but significant indexes $(r=-0.24 ; p<0.05)$, allowing inferring the presence of an inverse relationship, in which subjects showing high aggression blocking tend to have low self- aggression, and vice versa.

Regarding the relationship between features of SIP pain scale and the inter-relationship between its factor and total pain coping (TCR), the Pearson correlation test with significance level of 0.05 was also used. Regarding the relationship between features of the SIP pain scale and the inter-relationship between its factor and total pain coping (TCR), as already expected due to the formula that makes up the TCR index, i.e. TCR $=(\mathrm{COP}+\mathrm{COG})-$ $\mathrm{CAT}$, there were very strong significant correlations between total direct coping and direct coping $(\mathrm{r}=0.83 ; \mathrm{p}<$ $0.001)$ and also strong correlations with the SIP cognitive scale $(r=0.64 ; \mathrm{p}<0.001)$, indicating that these two features directly influence the overall ability of coping with pain by athletes. In opposition, catastrophizing showed a strong and significant but inverse relationship with total coping $(\mathrm{r}=-0.43 ; \mathrm{p}<0.001)$, i.e. subjects who tend to despair with the presence of lesions, those that become pessimists, think in pain all the time, feel that it is impossible to tolerate pain and essentially give up their condition, have less ability to cope with pain, which acts as a general indicator of athletes' ability to play their role in experiencing physical injury or painful situations.

\section{Conclusions}

In conclusion, it is important to emphasize the need for further investigations involving aggression in sport with the aim of analyzing the dimensions and conditions for its occurrence, considering that there are few studies on aggressive behavior in sport in literature, allowing different perspectives on the phenomenon. Thus, quantitative and qualitative studies on the perceptions of aggression among individuals of different ages, competitive levels, modalities, etc. should be carried out, which are vital for the understanding of this complex phenomenon [25].

Therefore, the analysis of aggression in sports in its forms and interpretations requires a sociocultural framework, and especially a focus on the sport modality under study. The definition of a behavior as hostile or reactive and instrumental aggression depends on the type of sport, its rules, position of players on the team (offense or defense) and the observer's interpretation.

Due to the lack of tools for the specific sporting context in our country, studies on the use of tests in some countries-Portugal, Spain and Ibero-American countries (including Brazil), Almeida et al. [26] pointed out some constant problems as the use of inadequate testing for some situations and the lack of clear adaptation of tools for the different regions of the country, among others.

Thus, there is an increasing need for a greater variety of tools to measure constructs in sports, considering that themes such as motivation, personality, aggression and violence, leadership, group dynamics, psychological well-being, thoughts and feelings of athletes and various other aspects of sports and physical activity have required studies and performance of professionals, since the technical level of athletes and high-performance teams is more balanced, with special emphasis on emotional preparation, regarded as the differential.

\section{References}

[1] Vieira, V.C.R., Priore, S.E. and Fisberg, M. (2002) A atividade física na adolescência. Adolescencia Latinoamericana, 3. http://ral-adolec.bvs.br/scielo.php?script=sci arttext\&pid=S1414-71302002000100007\&lng=es\&nrm=iso 
[2] Barbosa, D.J. (1991) O adolescente e o esporte. In: Maakaroun, M.F., Souza, R.P. and Cruz, A.R., Eds., Tratado de adolescência: Um estudo multidisciplinar. Cultura Médica, Rio de Janeiro.

[3] Engstrom, R., Johansson, M., Tornkvist, M. and Forssblad, M. (1990) Does a Major Knee Injury Definitely Sideline an Elite Soccer Player? American Journal of Sports Medicine, 18, 101-106. http://dx.doi.org/10.1177/036354659001800118

[4] Bajin, B. (1982) An Analysis of Injuries in Amateur Sport, in Particular Women's Gymnastics. Unpublished Observations. Canadian Gymnastic Federation, Ottawa.

[5] Gauron, E.F. and Bowers, W.A. (1986) Pain Control Techniques in College-Age Athletes. Psychological Reports, 59, 1163-1171. http://dx.doi.org/10.2466/pr0.1986.59.3.1163

[6] Yaffe, M. (1983) Sports Injuries-Psychological Aspects. British Journal of Hospital Medicine, 224-232.

[7] Rubio, K. and Godoy Moreira, F. (2007) A representação da dorematletasolímpicosbrasileiros. Revista Dor, 8, 926935.

[8] Godoy Moreira, F. and Rubio, K. (2008) A dor em corredores com fascite plantar: O uso da acupuntura. Revista Dor, 9 , 1290-1296.

[9] Meira Jr., C.M., Tani, G. and Manoel, E.J. (2001) A estrutura da prática variada em situações reais de ensinoaprendizagem. Revista Brasileira de Ciência e Movimento, 9, 55-63.

[10] Dogan, B. (2004) The Effects of an Individual's Athletic Participation and Trait Anxiety on Aggressive Behaviours outside Sport. Sport Psychologist, 15, 578.

[11] De Castro Bidutte, L., Azzi, R.G., Raposo, J.J.B.V. and Almeida, L.S. (2005) Agressividade em jogadores de futebol: Estudo com atletas de equipes portuguesas. Psico-USF, 10, 179-184. http://dx.doi.org/10.1590/S1413-82712005000200009

[12] Piotrowski, C. (2000) How Popular Is the Personality Assessment Inventory in Practices and Training. Psychological Reports, 86, 65-66. http://dx.doi.org/10.2466/pr0.2000.86.1.65

[13] Meehl, P.E. (2000) The Dynamics of "Structured" Personality Tests. Journal of Clinical Psychology, 56, $367-373$. http://dx.doi.org/10.1002/(SICI)1097-4679(200003)56:3<367::AID-JCLP12>3.0.CO;2-U

[14] Rubio, K. (2007) A Avaliação em Psicologia do Esporte e a Busca de Indicadores de Rendimento. In: Rubio, K., Org., Instrumentos de Avaliação em Psicologia do Esporte, Casa do Psicólogo, São Paulo, 13-26.

[15] Thomas, A. (1994) Esporte: Introdução à Psicologia. Ao Livro Técnico, Rio de Janeiro.

[16] Faleiros-Souza, F.A.E. and Da Silva, J.A. (2004) Avaliação e mensuração da dor em contextos clínicos e de pesquisa. Revista da Sociedade Brasileira para Estudo da Dor, 5, 408-429.

[17] Meyers, M.C., et al. (1992) Predicting Pain Response in Athletes: Development and Assessment of the Sports Inventory for Pain. Journal of Sport \& Exercise, 14, 249-261.

[18] Meyers, M.C., et al. (2008) Coping Skills of Olympic Developmental Soccer Athletes. International Journal of Sports Medicine, 29, 1-7. http://dx.doi.org/10.1055/s-2008-1038679

[19] Meyers, M.C., Bourgeois, A.E. and Leunes, A. (2001) Pain Coping Response of Collegiate Athletes Involved in High Contact, High Injury Potential Sport. International Journal of Sport Psychology, 32, 29-42.

[20] Pasquali, L. (1999) Instrumentos psicológicos: Manual prático de elaboração. LabPAM/IBAP, Brasília.

[21] Ryan, M.K., Williams, J.M. and Wimer, B. (1990) Athletic Aggression: Perceived Legitimacy and Behavioral Intentions in Girl's High School Basketball. Journal of Sport and Exercise Psychology, 12, 48-55.

[22] Silva, E.M., Rabelo, I.S. and Rubio, K. (2010) A dor entre atletas de alto rendimento. Revista Brasileira de Psicologia do Esporte, 3. http://pepsic.bvsalud.org/pdf/rbpe/v3n1/v3n1a06.pdf

[23] Lurie, Y. (2006) The Ontology of Sports Injuries and Professional Medical Ethics. In: Loland, S., Skirstad, B. and Waddington, I., Eds., Pain and Injury in Sports: Social and Ethical Analysis, Routledge, New York, 200-210.

[24] Duffy, S.P., McLean, S.L. and Monshipouri, M. (2011) Pearson's r Correlation. Recuperado em 20 de fevereiro de 2011. http://faculty.quinnipiac.edu/libarts/polsci/Statistics.html

[25] Stephens, D.E. (1998) Aggression. In: Duda, J.L., Ed., Advanced in Sport and Exercise Psychology Measurement, Fitness Information Technology, Morgantown.

[26] Almeida, L.S., Prieto, G., Muñiz, J. and Bartram, D. (1998) O uso dos testes em Portugal, Espanha e Países Iberoamericanos. Psychologica, 20, 41-55. 
Scientific Research Publishing (SCIRP) is one of the largest Open Access journal publishers. It is currently publishing more than 200 open access, online, peer-reviewed journals covering a wide range of academic disciplines. SCIRP serves the worldwide academic communities and contributes to the progress and application of science with its publication.

Other selected journals from SCIRP are listed as below. Submit your manuscript to us via either submit@scirp.org or Online Submission Portal.
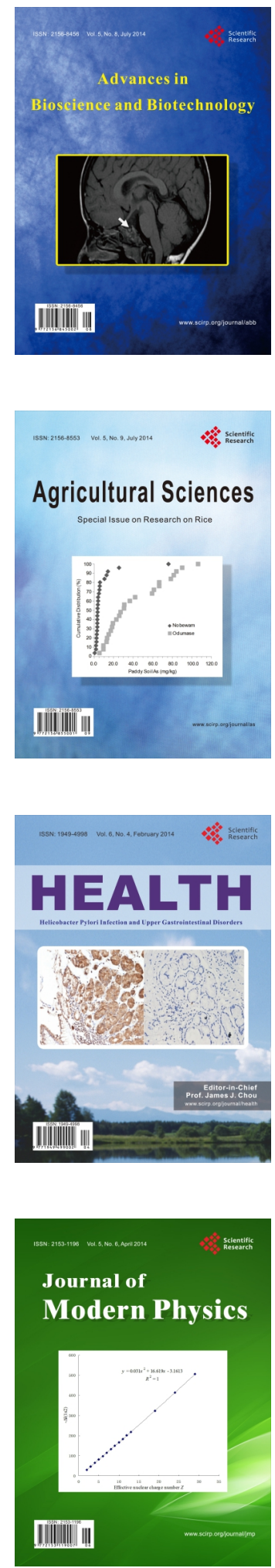
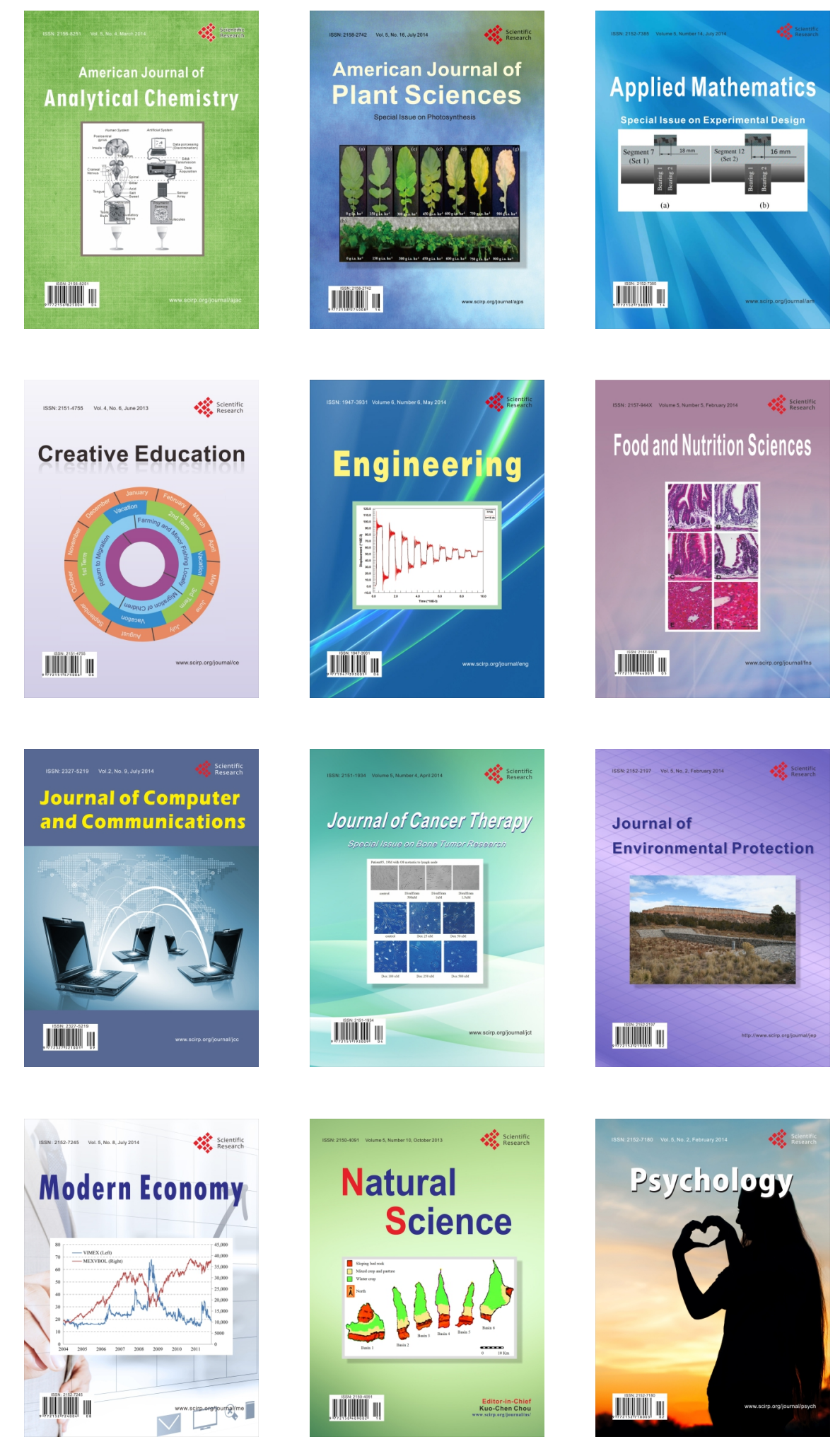